is increasing relative to the estimated release rate of nitrogen from fossil fuel sources (see figure). Global fertilizer consumption in 1975 (the date of the global atmospheric nitrogen budget used by Mayewski et al.) was about three times the estimated global emissions from fossil fuel sources. But from 1975 to 1985 , global fertilizer nitrogen consumption increased about $62 \%$ (ref. 3) compared with an increase of about $60 \%$ for nitrate concentrations in snow, whereas global fossil fuel use increased only $21 \%$ (ref. 4). Global nitrogen fertilizer consumption in 1988 was therefore about 4.2 times larger than the probable sources of tropospheric nitrogen derived from fossil fuel emissions.

Much of the applied nitrogen fertilizer may return to the atmosphere within one year, especially in warmer climates. Estimates vary widely with soil type, but up to $80 \%$ of the applied nitrogen may be lost to the troposphere as gaseous nitrogen (such as $\mathrm{NH}_{3}, \mathrm{~N}_{2}$ and $\mathrm{N}_{2} \mathrm{O}$, refs $5-8$ ). According to one rough estimate", $36-50 \%$ of the fertilizer escapes to the atmosphere depending on whether fertilizer nitrogen goes into the plant or animal industrial food chain.

Extensive global consumption of nitrogen fertilizer began in the late 1950 s, when nitrate concentration in ice from both the South Pole and south Greenland also began to increase rapidly (see figure). The correlation between nitrogen fertilizer consumption and nitrate deposition at the South Pole station ' $T$ ' reported by Mayewski et al.' is very good (see figure). This correlation is consistent with the hypothesis, but does not prove it.

Thus, the nitrogen in fertilizers is a much larger potential source of troposphere gaseous nitrogen than fossil fuel sources. A significant amount of the fertilizer source is known to 'leak' into the troposphere, and the recent rise in nitrate concentration in dated Antarctic snow samples coincides with the rise in fertilizer consumption. If this hypothesis is correct, then a difficult additional dimension must be addressed to understand and respond to the complex problem of global climate change.

\section{Department of Marine Sciences,}

Louisiana State University,

Baton Rouge, Louisiana 70803, USA

1. Mayewski. P. A. \& Legrand, M. R. Nature 346, 258-260 (1990)

. Mayewski, P. A. et al. Nature 346, 554-556 (1990) . Annual Statistical Yearbook (United Nations, 1951-89) . Energy Statistics Yearbook (United Nations, 1986).

5. Ehhalt, D. H. \& Drummond, J. W. in The Tropospheric Cycle of NO (eds Georgii, W. H. \& Jaeschke, W.) 219-251 (Reidel, Boston, 1982).

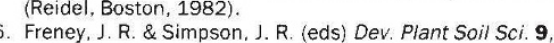
(1983).

7. Rolston, D.E. in Denitrification. Nitrification, and Atmospheric Nitrous Oxide (ed. Delwiche, C. C.) 127-149 Wiley, New York, 1981)

8. Bremmer, J. M. \& Blackmer, A. M. Science 199, 295-296 (1978).

9. Delwiche, C. C. in Denitrification, Nitrification, and Atmospheric Nitrous Oxide (ed. Delwiche, C. C.) 1-15 (Wiley, New York, 1981

\title{
Levitation of organic materials
}

SIR - We have succeeded in levitating at room temperature 'nonmagnetic' materials by means of a strong inhomogeneous static magnetic field. Such materials are in fact weakly diamagnetic and, when subjected to a magnetic field gradient, tend to be driven from regions of high field to those of lower field. When the resulting force is upwards and stronger than gravity, levitation occurs.

The critical criteria for levitation are the intrinsic magnetic property of the diamagnetic material (the specific magnetic susceptibility) and $G$, the gradient of the square of the magnetic field. For completeness, we also report $B$, the field at which the coils were driven to obtain such a gradient.

In the $5-\mathrm{cm}$ cylindrical room-temperature bore of the hybrid magnet of the Service National des Champs Intenses (Grenoble), we have levitated various diamagnetic solids and liquids. Pure samples of bismuth and antimony were levitated with $G_{\mathrm{Bi}}=729 \mathrm{~T}^{2} \mathrm{~m}^{-1}, B_{\mathrm{Bi}}=15.87 \mathrm{~T}$ and $G_{\mathrm{sh}}=1,208 \mathrm{~T}^{2} \mathrm{~m}^{-1}, B_{\mathrm{sb}}=18.75 \mathrm{~T}$, respectively, values in very good agreement with calculations based on magnetic susceptibility data (R. C. Weast, Handbook of Chemistry and Physics 1972-73). Pieces of wood and plastic were levitated with $1,648 \mathrm{~T}^{2} \mathrm{~m}^{1}<G_{n}<1,753 \mathrm{~T}^{2} \mathrm{~m}^{-1}, 21 \mathrm{~T}<$
$B_{n}<21.5 \mathrm{~T}$ and $G_{\mathrm{p}}=1,923 \mathrm{~T}^{2} \mathrm{~m}^{-1}, B_{\mathrm{p}}=$ $22.28 \mathrm{~T}$, respectively. Water, ethanol and acetone were levitated with $2,961 \mathrm{~T}^{2} \mathrm{~m}^{-1}<$ $G_{\mathrm{u}}<3,097 \mathrm{~T}^{2} \mathrm{~m}^{-1}, 26.5<B_{\mathrm{u}}<27 \mathrm{~T}, 1,445$ $\mathrm{T}^{\prime \prime} \mathrm{m}^{-1}<G<1,648 \mathrm{~T}^{2} \mathrm{~m}^{-1}, 20 \mathrm{~T}<B<21$ $\mathrm{T}$ and $1,862 \mathrm{~T}^{2} \mathrm{~m}^{1}<G_{\mathrm{a}}<2,086 \mathrm{~T}^{2} \mathrm{~m}^{-1}, 22$ $\mathrm{T}<B_{\mathrm{a}}<23 \mathrm{~T}$, respectively. Values for the liquids were higher than expected and may result from wetting effects in the apparatus.

We have studied the levitation of graphite in a lower field magnet with a much larger bore $\left(G_{\mathrm{g}}=140 \mathrm{~T}^{2} \mathrm{~m}^{-1}\right.$ and $B_{\mathrm{g}}=5.25$ $\mathrm{T})$. We have confirmed that the levitation was very stable, without any contact with the magnet bore.

Our technique could be used to provide a contactless, microgravity environment for the elaboration of a wide range of materials. The case of organic materials is of great interest as they all have almost the same specific diamagnetic susceptibility, high enough to achieve levitation in superconducting magnets.

E. BEAUGNON R. TOURNIER

CNRS, Centre de Recherule sur les

Très Basses Températures,

Laboratoire associé á l'université

Joseph Fourier,

25 Ave des Martyrs,

38042 Grenoble Cedex, France

\section{Steady shine}

SiR-Gry and Bonnet-Bidaud's claim that the alleged ancient red colour of Sirius was due to the obscuring of Sirius by a globule is not corroborated by the historical record. There is no evidence for a fainter Sirius in the past. Ptolemy's brightness estimates are unreliable as the 14 other first-magnitude stars he listed range from stars as bright as Canopus $(V=-0.72)$ to stars as faint as Denebola $(V=+2.14)$ and Acamar $(V=+3,06)$. In fact, both Manilius and Ptolemy identified Sirius as the brightest star in the night sky. Its unchanged brightness is further corroborated by ancient Babylonian and Hellenistic observations of its heliacal risings and settings. These phenomena depend on a parameter called the arcus visionis, which is correlated with the stellar brightness. The observations all result in an arcus visionis for Sirius comparable to its modern value.

The Chinese record by Sīmă Qiān (Shüji) is more correctly translated as: "To the east [of a previously discussed group of stars] there is a large star called Láng [= Sirius]; when Láng shakes its horns [scintillates?] and changes colour, there will be many robberies and thieves." According to the eighth-century commentator Zhāng Shŏujié "Láng is a star, situated southeast of Shēn [= Orion]. Láng stands for a campaigning general and governs robberies and pillage. It is predicted that people turn against each other when Láng changes position. When the colour [of Láng] is yellow or white and bright, it signifies good fortune; if the horns [rays?] turn red, military disturbances will arise. When Venus, Jupiter or Mars guard [= become stationary near] Láng, the same applies." The Shiji lists many more prognostics based on colour and brightness changes of other bright stars, none of which is currently known to be intrinsically variable. Apparently, these variations were all due to atmospherical scintillation or extinction. In fact, Sīmă Qiān confirms that the undisturbed colour of Sirius resembles the colour of Venus.

Arguments have been made ${ }^{2-5}$ for an unchanged bluish-white colour for Sirius during the past few millennia. The occasional references to a reddish Sirius (Babylonian omen texts, Horace, Seneca, Ptolemy and so on) are explained more naturally as referring to observations of Sirius near the horizon for calendrical and astrological purposes ${ }^{6}$.

\section{Museum Boerhaave, Postbox 11280 .}

2301 EG Leiden,

The Netherlands

1. Gry, C. \& Bonnet-Bidaud, J.M. Nature 347, 625 (1990).
2. van Gent, R.H. Nature 312, 302 (1984).
3. Tong, B. Tang Nature 319, 532 (1986).
4. van Gent, R.H. Nature 325, $87-89$ (1987).
5. van Gent, R.H. The Observatory 109, 23-24 (1989).
6. Rowan-Robinson, M. Universe p. 25 (Longman, 1990). 